Received: 05/07/2018

Revision: 01/10/2018

Accepted: 07/10/2018

OnlineFirst: 13/12/2018

\title{
Malaysian Rural Secondary School Students' Attitudes towards Learning English as a Second Language
}

\section{Farah Zulkefly}

Faculty of Educational Studies, Universiti Putra Malaysia (UPM), 43400 UPM Serdang, Selangor Darul Ehsan, Malaysia, farahfza2@gmail.com

\section{Abu Bakar Razali}

Dr., corresponding author, Faculty of Educational Studies, Universiti Putra Malaysia, 43400 UPM Serdang, Selangor Darul Ehsan, Malaysia,abmr_bakar@upm.edu.my

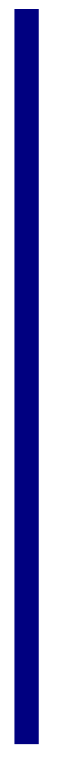

Students' attitudes towards learning English as a second language is not a new issue, yet much is to be known about the factors that actually affect the students' attitudes, especially those who live in rural areas that are known to have poor perceptions towards as well as poor performance in learning the English language as compared to Malaysian students who live in urban areas. Using Spolsky's (1989) Model of Second Language Learning and Gardner's (1985) Second Language Acquisition Theory, this study examines rural Malaysian students' attitudes towards learning English as a second language. The main objective is to investigate the individual elements or factors influencing rural secondary school students' attitude towards learning the English language. By employing a case study approach, four students from two different grade levels in a rural secondary school were purposively selected and individually interviewed and observed in their learning environments. The data were analysed using within and cross case analyses as well as thematic analysis, in which the authors read and annotated interview transcripts, identified themes, developed a coding scheme and coded the data. The findings suggest that there were two most significant factors influencing the students' attitudes towards the learning of English; i) lessons not catered to students' proficiency levels and interests, and ii) students' individual reactions to negative and positive experiences.

Keywords: English as a Second Language (ESL), rural school, students' attitudes, learning English, learning

\section{INTRODUCTION}

The Malaysian Education Blueprint 2013-2025 states that education will help Malaysians to have better lives in which it will lead to a brighter future. Through proper

Citation: Zulkefly, F., \& Razali, A. B. (2019). Malaysian Rural Secondary School Students' Attitudes towards Learning English as a Second Language. International Journal of Instruction, 12(1), 11411156. https://doi.org/10.29333/iji.2019.12173a 
education, the nation will be able to have good communication with people from various backgrounds, religions and ethnicity. Malaysia aims to make a big improvement in the education system. However, this improvement is not parallel with the English proficiency of most Malaysian students, particularly those staying in the rural areas (Ler, 2012). Being a global language, English is a must-know language in order for one to fit into the real world. For this reason, English plays a significant part in Malaysian Education system, where it is regarded as a second language and a language of knowledge, which can help Malaysians gain better employment and thus gain better social status. However, many students view English as a foreign language, which is spoken only during language lessons (Tom, Aiza, Awang \& Siti, 2013). Despite the fact that the learning of English is supposed to prepare individuals for the real world, Hiew (2012) claims that the eleven years of learning the English language does not do much help in improving the proficiency of the majority of Malaysian students.

The problem with students' lack of English language proficiency is most prominent among rural students in Malaysia. This is due to the inadequate exposure to the language itself as well as insufficient practice of English language (Rosli Talif \& Jayakaran Mukundan, 1994; Jamali Ismail \& Hasliza Aris, 2002; Ler, 2012). Jamali Ismail and Hasliza Arif (2002) stated that the secondary school students in rural areas fail to see the need to use English in their lives. Consequently, both their motivation to learn the English language and their proficiency in the language decrease. Often times, attitudes are also shaped by the psyche of the people in their immediate surroundings, such as parents and peers, which "develop early in childhood and are the result of parents and peers' attitudes" (Brown, 2000 p.180). Attitudes towards a language, especially when it comes to one's belief towards the worth of the language usually begins within the students' own psyche.

\section{STUDENTS' ATTITUDES IN LEARNING ENGLISH AS A SECOND LANGUAGE}

It is very crucial for students to have positive attitudes in order for them to be better in learning a language. Gardner and Lambert (1959) stated that success in language learning is related to attitudinal variables. These variables are attitudes towards the language learned and towards the speakers of that language and culture. Learning a language is not a simple process where it involves internal and external factors (Wang, 2008).

In addition, Baker (1985) stated that if the need of acquiring the second or foreign language is not felt by students as important for them to function either within or outside their immediate community, they would most probably have a negative attitude toward the language. Hussein Islam (2014) stated that the level of activeness or passiveness of a student in class is highly dependent on his or her attitude. With regard to language learning, attitude can either be positive or negative (Youssef, 2012). Jain and Sidhu (2013) claimed that if one is to do well in language learning, attitude would be a major factor. This is because the attitude shapes the students' perceptions towards class, teachers and the curriculum itself. 
Ellis (2015) found that attitude is influenced by the students' beliefs about the target language culture and the students' own culture, which normally starts at home. Gajalakshmi (2013) believes that a successful language student should be able to identify themselves with the native speakers of that language. These students are the ones who would acquire or adopt various aspects of behaviours that mirror the target language culture or society. This is similar to Gardner's (1985) point which posited that second language (L2) students who look at the target culture in a positive way will learn the target language more effectively than those who have negative perception towards the targeted language culture. This means that they must have acceptance of the target language, which Gardner (2005) referred to as "individual's openness to taking on characteristics of another cultural/linguistic group" (p. 7). This concept of openness usually depends on how one perceives the language itself. Baker (1985) posited the idea that attitude towards a second or foreign language is connected with the language that students use at home and their cultural background, such as the support from family and society (or lack thereof).

Krogh and Slentz (2001) explained that language learning is easier when it is whole and relevant. This means that the language is both meaningful and functional to the student. Also, it is easier when the language is in context which refers to the aspects of real life, such as the conversations with people in their immediate surroundings. This idea is similar with Spolsky (1969) and Gardner and Lambert (1959) in which they stated that success in language learning is related to the attitudes towards the language learned and towards the speakers of that language and culture.

In the case of Malaysia, even though English is considered as the second language, and many Malaysian people can practice English very well, in certain places in Malaysia the English language is still considered as a foreign language, or worse, irrelevant to their lives. The issue with students' lack of English language proficiency is mostly among rural school students in Malaysia as they have insufficient exposure to the English language. Also, there is lack of English language practice among these students (Rosli Talif \& Jayakaran Mukundan, 1994; Jamali Ismail \& Hasliza Aris, 2002). Despite the fact that "Malaysian people in general accept and acknowledge the role of English as the national second language in Malaysia and its important role as a language of communication within the globalized society" (Abu Bakar, 2013, p.3), many students view English as a foreign language which is spoken only during language lessons (Tom, Aiza, Awang \& Siti, 2013).

From the review of the literature, there have been quite a number of studies that were done on students' attitudes on learning English as a second language, particularly on rural or suburban schools students. However, even though there has been a number of research done on this topic and topics similar to it in the Malaysian context, many of them were done quantitatively (for instance see Gajalakhsmi, 2013; Jain \& Sidhu, 2013; Ler, 2012; Rahimah et al., 2004; Thang, Ting, \& Nurjanah Mohd Jafar, 2011; Wang, 2008; ). And, while these quantitative studies have been very helpful in understanding this issue, there should be more qualitative research that can further illuminate this issue in depth. This is because according to Yin (2011), a qualitative research contributes 
insights into existing or emerging concepts that may help to explain human psyche, which in this study would be the students' attitude towards learning English.

It is therefore important to do an in-depth qualitative research that can help teachers, policymakers, teacher educators and researchers as well as parents and other stakeholders to understand that individual factors are very much connected on the attitudes students have towards the learning of English in school. Thus, an in-depth qualitative research on students' attitude towards learning English language can help to understand the in-depth issues to rural students' attitudes towards learning English and how these attitudes affect their learning of the English language.

\section{PROBLEM STATEMENT}

Despite the fact that "Malaysian people in general accept and acknowledge the role of English as the national second language in Malaysia and its important role as a language of communication within the globalized society" (Razali, 2013, p.3), many students view English as a foreign language which is spoken only during language lessons (Tom, Aiza, Awang, \& Siti, 2013). While students in urban areas tend to have better proficiency level of English as compared to students studying in rural areas (Rosli Talif \& Jayakaran Mukundan, 1994; Jamali Ismail \& Hasliza Aris, 2002), Malaysian students who are staying in remote or rural areas fail to see the need to use English in their life. This eventually leads to their lack of motivation and proficiency in the language (Jamali Ismail \& Hasliza Arif, 2002). This situation is quite disturbing because without seeing the practicality of using the second language in their community circle, there is a high tendency for these students in the remote areas to have a negative attitude towards learning the language

There is a pattern that students' attitude and achievement towards English is very much affected by the region of where they are staying. Apparently, students who are staying in secluded areas do not show positive attitude towards learning English. In a research done by Ler (2012) on students and teachers from different ethnic backgrounds and different levels of English language proficiency in six rural schools in Terengganu, Malaysia, it was found that both teachers and students felt that the extensive use of the native Malay language is one of the reasons why the English proficiency is poor among rural students. Ler stated that the rural setting, traits practices and culture are the factors causing the low proficiency of English. He came to a conclusion that "the rural cultural setting does affect the proficiency level of English among the students in rural schools" (p.12). He added that rural students are inclined to be more shy and reserved when it comes to learning English. The problem of low proficiency in English is very serious in rural areas where the failure rate in the English language subject is rather high (Rahimahet al., 2004). Thang, Ting and Nurjanah Mohd Jafar (2011) also mentioned that attitudes and motivation of these students who live in rural and remote areas towards learning English is believed to be among the factors to low proficiency and low passing rates in schools.

Therefore, this study aims to understand the attitudes of students studying in a rural school in a southern state in the Peninsular of Malaysia on the learning of English as a 
second language. This study specifically looks to examine what and how these factors affect the students' attitudes towards learning English. Thus, the study is guided by two questions, namely: (1) What are the factors influencing rural secondary school students' attitude towards learning the English language? and (2) How do these factors influence rural secondary school students' attitude towards learning the English language?

\section{METHOD}

\section{Research Design}

In this study, the researchers adopt the qualitative research approach and employ the case study design. A case study is concerned in the meaning people make of their lives in very particular contexts (Dyson \& Genishi, 2005). Bexter and Jack (2008) claim that "the case study methodology provides tools for researchers to study complex phenomena within their contexts" (p. 544). Thus, the case study design is suitable for this research because instead of just wanting to know what is the attitude of the students, the researchers aim to understand why and how the phenomenon (i.e., positive or negative attitudes) among students are developed.

\section{Sample Selection}

In choosing the participants, i.e., student-participants, the researchers engaged in a purposive sampling method through the suggestion of the gatekeepers (i.e., school administrators and teachers), and they also relied on the stratified purposeful sampling (particularly the maximum variation sampling technique) to get a wider range of students from each form or grade level. For the purpose of this study, the gatekeepers (i.e., school administrators) only allowed the researchers to focus on students in forms 1 and 2 (similar to grades 1 and 2 in the United States of America). In this study, the researchers selected participants from different classes indicating the different ages and form or grade levels, in which four students (i.e., two students from grades one and two) were chosen. Aside from the diversity in age, gender, and their English proficiency level, the participants chosen are from different ethnicities to reflect variation in the sample. This, according to Patton and Cochran (2002), would be useful to minimize sample bias. It also important to understand that this sampling technique does not intend to generalize the participants selected as representing all people in the population. It only aims to include a wider range of participants so that the research would not have obvious limitations (Patton \& Cochran, 2002). In order to purposely choose the correct research participants for the study using the maximum variation sampling technique, the researchers came up with selection criteria, in which they considered the students' personal and academic backgrounds, such as race, gender, and also their English language proficiency level(s). (See Table 1). 
Table 1

Criteria for participant selection

\begin{tabular}{ll}
\hline \multicolumn{1}{c}{ Participants (Students) } & \multicolumn{1}{c}{ Criteria } \\
\hline Number of students & $\begin{array}{l}4 \text { students (2 students from each class; forms or grade } \\
\text { levels 1 and 2) }\end{array}$ \\
\hline $\begin{array}{l}\text { Attitude of students (in regards to } \\
\text { the learning of English language) }\end{array}$ & $\begin{array}{l}\text { 1 student identified as having positive attitude; and 1 } \\
\text { student identified as having negative attitude }\end{array}$ \\
\hline Learning Experience & $\begin{array}{l}\text { Both students from forms or grade levels 1 and 2 } \\
\text { have to be from the same class to ensure they have } \\
\text { had similar experiences in the learning of English in } \\
\text { secondary school setting }\end{array}$ \\
\hline Ethnicity & $\begin{array}{l}\text { There should be at least one representative of Malay, } \\
\text { Chinese and Indian (i.e., three most prominent ethnic } \\
\text { groups in Malaysia) students among these 4 } \\
\text { participants }\end{array}$ \\
\hline Geographical Background & $\begin{array}{l}\text { All students must be the residents of the research } \\
\text { setting since they were born. }\end{array}$ \\
\hline
\end{tabular}

\section{Data Collection}

In this study, the researchers gathered the data from multiple sources and by using several qualitative research methods. The research methods that were used are face-toface semi-structured interviews, observations, and field notes.

\section{Face-to-face semi-structured interview sessions}

In this study, the researchers conducted two individual interviews on each student. The first interview with the students focused more on their personal and the familial backgrounds for the researchers to get better understanding about the students. The second interview session was done after collecting data in the observations and analysing related documents to understand how they view English language as well as their exposure towards the language. Also, the questions are designed to seek information about the aspects that influence their beliefs towards learning English language as well as to get to know the issues that they face when learning English. (See Appendix A).

\section{Observation sessions}

In order to have sufficient results, the researchers conducted a systematic observation in which they recorded the time and place of the observations, together "with a description of what is observed on one side and observer's comments on the other" (Dyson \& Genishi, 2006, p.60). In this systematic observation, the researchers adapted an observation protocol from The Classroom Observation Protocol for Undergraduate STEM (COPUS) by Smith, Jones, Gilbert, and Wieman (2013) to which they recorded the actions and reactions of the students during these lessons to indicate their attitudes towards the learning of the English language. The observation sessions were done at least three times for each student. 


\section{Field Notes}

The researchers took note of the observations as well as other important events and circumstances as a source of reference as well as the evidence of the data. Field notes were mostly taken to record the learning of and attitudes during English lessons, but also during other formal and informal learning sessions to record the students' attitudes towards the learning of the English language.

\section{Data Analysis}

In this research, the researchers did thematic analysis, in which they first compiled all the data (Yin, 2011), read, and made annotations on all the data received from each instrument (i.e., the interview sessions, the observations, the field notes and the learning documents). After that, the researchers started looking in detail at the data to start breaking them into parts. This process is also known as the disassembling of data process (Yin, 2011). They then reassembled the data (Yin, 2011) into the identified themes (Patton \& Cochran, 2002). At this stage, the researchers used the data from all the instruments and started to identify the themes where the major element would be individual factors. All these elements (main- and sub-elements) were grouped as themes in the analysis process.

After analysing all the data separately (according to the instrument and according to each participant, in which they repeated the same analytical process according to each of the participants based on each of their individual data collected from the research instruments), the researchers analysed and drew conclusions (Yin, 2011) from the overall data. In doing so, the researchers engaged in the triangulation process.

The triangulation was done in two ways, namely method triangulation and triangulation of sources. Method triangulation is done by analysing the data according to instruments. This means that the researchers analysed the data gathered from the different instruments used (i.e., the interview, the observation, the field notes and documents analysis) and triangulated the data. This is significant for the researchers to compare the data to check out the consistency of the data generated by different data collection methods. The divergence of these data provided the most insights for the research (Angen, 2000) as the researchers was able to see if there was any biasness during the data collection process be it from the participants or the researchers herself. Meanwhile, triangulation of sources required the researchers to analyse the data according to the source of the research (i.e., the student participants). These findings were triangulated to examine the consistency of research participants from within the same method (i.e., research instruments). This was to compare the data gained from participants with different points of view (Angen, 2000).

\section{Researcher's Biases/Ethics and Moral}

According to Maxwell (2009), there are seven things that can be considered in dealing with validity issues in a qualitative research, namely intensive long-term (field) involvement, "rich" data, respondent validation, search for discrepant evidence and negative cases, triangulation, quasi-statistics and comparison. In this study, the 
researchers fulfilled at least fiveout of the seven criteria which are; intensive long-term (field) involvement, "rich" data, respondent validation, triangulation and comparison.

In order to ensure that the research was carried out with integrity and rigor, particularly due to the fact that qualitative research requires the researchers to be involved with the participant quite closely and to be in the field for somewhat a long period of time, the researchers engaged in detailed observations, interviews and document reviews to get "rich" data. Throughout the data collection process (i.e., interview, observation, field notes, and document analysis) the researchers constantly checked with the participants whether or not her interpretations of the data analysed and interpreted are the same with what the respondents intend to convey. Lastly, the researchers made comparison of the data received with the research done in other settings. In doing so, the researchers constantly compared all of the data collected from each participant in determining the answers for the research questions. The comparative procedure involves not only the various data collected on each individual participant (i.e., within-case analysis) but also across participants (i.e., cross-case analysis) (Yin, 2011). Lastly, the researchers also engaged in detailed audit trail recording system to keep track of all the details and decisions that are made during the data collection and data analysis phases. All of these records were done to ensure validity and reliability as well as to ensure that the research is done ethically and responsibly.

\section{FINDINGS}

\section{Form 1 Participants (Devi and Fahim)}

Devi and Fahim (pseudonyms) live in a multiracial neighbourhood. In the case of Devi, she uses English when she talks to her cousins who live nearby as her cousins do not communicate in Tamil (i.e., Devi's mother tongue). This created a positive experience for Devi and her cousins (whose first language is English) to practice the English language in their interactions. Devi, had also been exposed to such circumstances through her parents, who created competitions between Devi and her elder sister, for which they compete on who can speak English better; ergo, nurturing a positive sense of competition between the two siblings to speak better English. Devi stated,

"I love the language because since I was a child I love to watch English cartoons like Frozen, Zootopia... Mickey Mouse... and I love English."

(Devi, interview session, Jan 21, 2017)

Moreover, her parents provided sufficient English materials (English reading materials as well as English videos and movies), for her benefit since she was young, henceforth, developing her interest towards the language even more. They bought their children compilations of famous fairy tales, such as Cinderella, Snow White, Rapunzel, and so on. Aside from subscribing to the Disney Channel, they also bought CDs of English movies and cartoons for the girls to watch, and sometimes even brought the girls to the movie theatre to watch English movies or cartoons. Hence, the roles of Devi's parents in exposing her and her sister to the English environment since they were kids had significantly affected the way she positively perceives the language. 
Fahim, on the other hand, never used English as a medium of communication with anyone in his house, and not even with anybody outside of his house. School (i.e., during English lessons), was the only place for him to use English, if at all. Interestingly, he claimed that he was aware of the importance of the language. He believed that English is important for people to get a job. However, he also claimed that he had little interest towards learning or using the English language because, according to him, English was difficult to learn. During an interview session done with him, whenever asked for reasons of him not showing interest in learning English, 90\% of the answers would be either "It's hard" or "I don't understand" (Fahim, interview session, Jan 22, 2017).

Ironically, Fahim who claimed to have problem understanding English language, did not actually put much effort in improving the language. He rarely watched English movies and videos, and he did not listen to English songs because again, "I don't understand", he said (Fahim, interview session, Jan 22, 2017). Fahim also hardly made any effort trying to be better at the language. For instance, he was not paying attention when the teacher was teaching, and he was not discussing with his friends during the group work assigned. When asked, he admitted to having acted in such way because he found the language too hard to comprehend that he eventually lost his interest in learning. This ironic behaviour is parallel to the findings of a study done by Tsuda (2003) on tertiary level Japanese students, where some of the participants, despite acknowledging the importance of English, claimed to not like the language because it was too hard for them, just like how it was for Fahim. Hence, Fahim feels discouraged, and has no confidence to actively participate in the learning of the language be it directly or indirectly.

While his struggle to learn the English language may explain Fahim's negative behaviour towards it, there is also perhaps a possibility that Fahim was not actually aware of the importance of English in the first place. He could have just said that English is important just because everybody else around him seemed to think so, making him agree that English is important for him to get a good job in the future. This possible lack of awareness is quite worrying. According to Kalra (2015) "language awareness covers a wide spectrum of fields" (p.214). Among these awareness are; understanding the way a language works and how it is learned and used (Kalra, 2015). These senses of awareness would lead into having better attitudes and to feel interested to learn the language. In regard to the case of Fahim, one might wonder if he has this awareness towards the importance of learning and practicing the English language; or perhaps his struggle towards learning the language really is that overwhelming that even by being aware of the importance of the English language, he simply could not overcome his struggle.

\section{Form 2 Participants (Jason and Jonathan)}

In Jason's (a pseudonym) family English is not a commonly used language for communication purposes. However, it was evident from the interview and from the observation that Jason made his own efforts to create the English social interaction environment by speaking in English with his cousins, who were good in the English 
language whenever they came to his house. He claimed to be highly passionate about English. "I want to learn" he said (Jason, interview session, Feb 1, 2017). Hence, this was the effort for him to learn the English language. Meanwhile, for Jonathan (a pseudonym), because of his family's ethnic background and the major ethnic group in Jonathan's housing area is Indians, he prefers to use Tamil and he rarely practices the English language. Both Jason and Jonathan, were not provided with English reading materials at home. They were also not exposed to the English language by their parents. However, both of the participants were able to see the importance of the language, believing that the English language is essential for them to get good jobs and have better future.

Although both Jason and Jonathan were on the same page pertaining to the issue of the relevance of English in their future - despite not being provided with English materials at home - they seemed to be on two different pages in the way they act and react towards learning the English language. Jason, for one, has a great affinity for the English language, and would read English reading materials in the school's library and listen to English songs because he said through these activities, "I can learn new words" (Jason, interview session, Feb 1, 2017). However, he rarely watches English movies, saying that "They talk too fast in the movies", hence, not allowing him to learn English as much (Jason, interview session, Feb 1, 2017). Jonathan, on one hand portrays a typical behaviour of disinterest towards the language. During the interview, he disclosed the fact that he had never made any efforts to read any English materials in the school library, where there are abundance of materials provided. Also, he does not listen to English songs and watch any English videos/movies saying "I don't understand", upon being asked to give reasons for his behaviour (Jonathan, interview session, Feb 2, 2017). He also stated that even if he were to live in a community that speaks English, he would rather communicate in Malay. On the other hand, Jason made full use of opportunities that he had (i.e., read English materials in the library, talked in English with his cousins, listened to English songs, and completing his English homework), so that he could improve his English.

\section{DISCUSSION}

Based on the research findings, the participants felt that they would be a lot more interested and enthusiastic in learning English language if their English teachers were to change their teaching styles. In fact, the important role of the teachers has also been mentioned numerous times by the educational authorities as well as the parents. Students, parents, and educational authorities argued that the environment in English classrooms was not exciting enough to entice the students to learn the English language. This finding is cognizant of Gardner's (1985) Second Language Acquisition Theory, which, according to him, states that if a teacher's methodology is not interesting enough, "it is unlikely that positive attitudes will be developed" (p. 8). In addition, Gardner (1985) also stated that negative perception towards English learning experience would do no good in developing positive attitudes towards the learning of the language. Even worse, if students feel anxious about learning the English language, it will only lead to debilitation of the language learning process (Du, 2009; Morreale, 2011; Tanveer, 
2007). Therefore, it is very crucial for both teachers and students to have effective communication between each other so as to help each other to improve what needs to be improved and change what needs to be changed, in order to have a better language learning experience.

In another point, aside from not favouring the teachers' teachings styles, some students were portraying negative attitudes towards learning the English language due to the past experiences, such as humiliation caused by either their teachers' or their friends' whenever they try to practice English. This eventually impeded them from becoming more active during English lessons. Some students claimed to have been teased and laughed at by their friends for pronouncing some words wrongly. Agreeing that such situation has certainly affected the way they behaved in English classes, some students confessed that the pain of these negative incidences is still present. That said, interestingly, there are also some students who took these negative incidences in a different manner. Some students admitted to being humiliated by their teachers for not being able to perform well in the English subject. These students, took these negative experiences as a challenge and as a tool for motivation for them to prove their ability in learning the English language. Apparently, the pressure of humiliation has turned these "rocks" into shining diamonds. In this regard, these particular students chose to not let themselves be overcome by their hurt feelings, rather, they use the negative experiences as a catalyst to improve themselves.

To conclude, the findings suggest that there were two most significant psychological factors influencing the students' attitudes towards the learning of English; i) lessons not catered to students' proficiency levels and interests, and ii) students' individual reactions to negative and positive experiences. Thus, it is important for teachers in particular, to ensure that students' psyche are not negatively affected by the lack of interesting English lessons and attending to students' negative experiences in learning the English as well as not to provide (and try to deal with) such negative experiences so that the language learning process would not be hindered and the students would have better attitudes towards learning the English language

\section{IMPLICATIONS}

Based on the findings, among the most highlighted issue regarding rural school students' attitude towards learning English as a second language is the lack of need in using the English language, be it in the school or at home. The findings suggest that the students are able to see the importance of the English language, but unable to see the immediate need of using English as a medium of communication, especially when conversing with others who share the same mother tongue as it would be more effective and inclusive to use their own language rather than using English. While this might be true, it has indirectly influenced the students rather negatively in portraying negative attitude to learn the English language. In other words, the students do not have impetus or immediate need to learn the language as they feel that they would be able to survive living in the community, even without a command of English language. 
Hence, creating the need to know, appreciate, and practice the English language is essential to boost the students' motivation to want to learn this language. The lack of acceptance of English language still occurs in rural areas despite the people in these rural areas understand and acknowledge its importance. The English environment, especially in rural areas, needs to first be created, involving not only the students and the English teachers, but also the school community as a whole, and most importantly, the parents, as they are involved directly with their children at home. Therefore, having important stakeholders, such as policymakers, curriculum developers, parents, and the community to be involved directly and indirectly with creating the need for using the English language at home, in school, and within the society is really important and will only work if all of the people involved play their roles and cooperate with one another.

\section{CONCLUSION}

Research on the students' attitudes towards learning the English language, especially those in the rural areas, is important because by investigating the rural students' attitudes towards learning the English language, more understanding can be achieved about the lack of English proficiency amongst rural students in Malaysia. More importantly, this research helps in understanding individual elements that contribute to the students' attitudes towards learning English. By understanding these elements, researchers, teachers, administrators, policymakers, curriculum developers and other stakeholders will be able to understand the reasons behind the students' positive and negative attitudes when learning the English language.

The authors believe that in order to develop positive attitudes among secondary school English language learners, particularly the ones living in rural areas, it requires cooperation from many people (i.e., the students, the teachers, the parents, and the educational authorities). Everybody is responsible for the education of the younger generation, and it is important that all of them play their roles well so that the younger generation can benefit from their education to ensure the wellbeing of themselves, their school, their families, and the society as well as the nation.

\section{REFERENCES}

Abu Bakar Mohamed Razali. (2013). Malaysian teachers' conceptions and uses of digital technology in English writing instruction: A multiple case study (Doctoral dissertation). Retrieved from ProQuest Dissertations and Theses. 3587444.

Angen, M.J. (2000). "Evaluating interpretive inquiry: Reviewing the validity debate and opening the dialogue." Qualitative Health Research, 10(3), 378-395. doi: $10.1177 / 104973230001000308$

Baker, L. R. (1985). Explaining attitudes: a practical approach to the mind. Cambridge University Press.

Brown, H. D. (2000). Principles of language learning and teaching. New York: Pearson.

Dyson, A. H. \& Genishi, C. (2005). On the case. New York: Teachers College Press. 
Ellis, R. (2015). OAL: Understanding Second Language Acquisition (2nd ed). Oxford Applied Linguistics. Oxford University Press.

Gajalakshmi. (2013). High School Students' Attitude towards Learning English Language. International Journal of Scientific and Research Publications, 3(9), pp. 1-7

Gardner, R. C., (1985). Social Psychology and Second Language Learning: The Role of Attitudes and Motivation. London: Edward Arnold.

Gardner, R. C. (2005). Integrative motivation and second language acquisition. Canadian Association of Applied Linguistics/Canadian Linguistics Association Joint Plenary Talk, London, Ontario.

Gardner, R. C. \& Lambert, W. E. (1959). Motivational variables in second-language acquisition. Canadian Journal of Psychology/Revue Canadienne de Psychologie, 13(4), pp. 266-272. doi: http://dx.doi.org/10.1037/h0083787

Hiew, W. H. (2012). English language teaching and learning issues in Malaysia: learner's perceptions via Facebook dialogues journal. International Refereed Research Journal, III(1).

Hussein Islam Abdullah \& Parilah Mohd Shah. (2014). Motivation and attitudes towards learning English among undergraduates in National University of Malaysia (UKM). International Journal of English Education, 3(4), pp. 209-227.

Jain, Y., \& Sidhu, G. K. (2013). Relationship between anxiety, attitude and motivation of tertiary students in learning English as a second language. Procedia - Social and Behavioral Sciences, 90, pp. 114-123. doi:10.1016/j.sbspro.2013.07.072

Jamali I. \& Hasliza A. (2002). The need to speak English in Malaysia: what do learners say. In Trends in English language teaching: Selected papers from the Malaysia International Conference on English Teaching (MICELT) 1996 and 1998 (pp. 35-43). Serdang: University Putra Malaysia Press.

Kalra, M. (2015). Creating an awareness among students about the importance of english language. International Journal of Social Science and Humanities Research, $3(1)$, pp. 213-216.

Krogh, S. \& Slentz, K. (2001). The early childhood curriculum. New York: Routledge.

Ler, E. C. (2012). Cultural factors affecting English proficiency in rural areas. Advances in Language and Literary Studies, 3(1), pp. 1-23. doi:10.7575/aiac.alls.v.3n.1p.1

Maxwell, J. A. (2009). Designing a qualitative study. In Leonard Bickman \& Debra J. Rog (Eds.), The Sage handbook of applied social research methods (2nd ed), pp. 214253). Thousand Oaks, CA: Sage

Patton, M. Q. \& Cochran, M. (2002). A guide to using qualitative research methodology. Medecins Sans Frontiers. Retrieved December, 12, 2015 from https://evaluation.msf.org/sites/evaluation/files/a_guide_to_using_qualitative_research_ methodology.pdf 
Rahimah A. W.; Mohd Sahar S.; Fozilah A. H., \& Hamidah A. (2004). Research on issues pertaining to the teaching of English in FELDA schools in Segamat. Retrieved from

http://manisportal.kpwkm.gov.my/docs/shared/KPWKM/Kajian\%20Inventori\%20Kajia n\%20Pembangunan\%20Sosial\%20di\%20Malaysia\%202001\%202005/J0174.pdf

Rosli Talif \& Jayakaran M. (1994). Using literature in an advantaged situation: issue and prospects. The English Teacher, 17, pp. 1-5.

Smith, M. K., Jones, F. H., Gilbert, S. L., \& Wieman, C. E. (2013). The Classroom Observation Protocol for Undergraduate STEM (COPUS): A new instrument to characterize university STEM classroom practices. CBE-Life Sciences Education, 12(4), 618-627. Retrieved from http://www.cwsei.ubc.ca/resources/files/COPUS_protocol.pdf

Spolsky, B. (1969). Attitudinal aspect of second language learning. Language Learning, 19(3-4), 271- 283. doi: 10.1111/j.1467-1770.1969.tb00468.x

Spolsky, B. (1989). Conditions for second language learning: Introduction to a general theory. Oxford: Oxford University Press. Retrieved from bookZZ.org

Thang, S. M.; S. L. Ting, \& Nurjanah M. J. (2011). Attitudes and Motivation of Malaysian Secondary Students towards Learning English as a Second Language: A Case Study. The Southeast Asian Journal of English Language Studies, 17(1), pp. 40-54.

Tom, A. A., Aiza, J., Awang, R., \& Siti, H. (2013). Factor contributing to communication apprehension among pre-university students. Academic Journal of Interdisciplinary Studies, 2(8), pp. 65-669.

Youssef, A. M. S. (2012). Role of motivation and attitude in introduction and learning of English as a foreign language in Libyan high schools. International Journal of Linguistic, 4 (2), pp. 366-375.

Yin, R. K. (2011). Qualitative research from start to finish. New York: Guilford Publications. 


\section{Appendix A: Semi-Structured Interview Questions}

Thank you for taking time to meet with me.

I am planning to audio record this interview. Do I have your permission to do so? (Press "record" on the audio recorder. State student's name and date)

I would like to talk with you about your personal and social backgrounds. May I ask you some questions?

i) Personal Backgrounds

Can you tell me about yourself?

-How old are you?

-Which class are you from?

ii) Social background

Where do you live?

-How long have you been in rural area?

-In which part of this rural plzace do you live specifically? (Name of the residential area)

-Have you ever lived at any other place? Where?

-What is the major race in your residential area?

-Do you mix well with your neighbours?

-If you talk to your neighbours, what is the language that you would usually use?

Can you tell me about your family?

- What do your parents do for living?

- Do you have any English reading materials (aside from the ones provided by school) in your house? How many reading materials do you have roughly?

- Do any of your family members like to read/write/listen/communicate/watch any English materials?

-Do your parents know how to communicate in English?

- How often do you use English as a medium of communication at home?

International Journal of Instruction, January2019 • Vol.12, No.1 
iii) Personal background

What are your experiences in learning English language in school? Do you like it or not Why?

-Do you ever get complimented by anyone (teachers/friends/family members/ others) because of your English proficiency?

-If yes, how did you feel about it at that time?

- Do you still feel the same now?

-Do you ever get insulted by anyone (teachers/friends/family members/ others) because of your English proficiency?

-If yes, how did you feel about it at that time?

- Do you still feel the same now?

- Do the way your English teacher teaches affect your interest in learning the language? Why or why not?

- Do you think your English teacher understands you well? Why or why not?

- Overall, do you perceive your English learning experience as something fun or the other way round? Why or why not?

iv) Attitude towards English Language Learning

What is your opinion about English learning?

- Do you think English is important? Why or why not?

- Do you like learning English at school? Why or why not?

- Do you always finish your English homework? Why or why not?

- Do you like to read English materials at school? Why or why not?

- Do you like to watch English videos/series/films? Why or why not??

- Do you like listening to English songs? Why?

- Do you like to be involved in the English language activities? Why or why not?

- Do you often visit the English Corner, in front of the school hall? Why or why not?

Are there any comments or thoughts that you would like to add before we end our interview today?

Thank you so much for your time. I really appreciate your thoughtful comments, and I enjoyed our conversation. 